\title{
PENGENALAN TEHNIK SADARI DI RT 15 KELURAHAN BULURAN KENALI
}

\author{
Nurfitriani ${ }^{1)}$, Julaecha ${ }^{2)}$ \\ 1) Program Studi D3 Keperawatan, Sekolah Tinggi Ilmu Kesehatan Baiturahim Jambi \\ 2) Program Studi D3 Kebidanan, Sekolah Tinggi Ilmu Kesehatan Baiturahim Jambi \\ email: nurfitriani_1173@yahoo.com
}

\begin{abstract}
Breast cancer is still a big problem in Indonesia, since $68.6 \%$ of women with breast cancer treatment kedokter disease on local advanced stage (IIIa and IIIb), while in the early stages (I and II) only 22.4\%. High number of incident breast cancer this should be a concern for the Government and society in General.The purpose of the realize is to know early detection/as the presence of breast cancer that can be performed in women of fertile age. It turns out that 75 $82 \%$ of breast malignancy found upon inspection SADARI and can lower the mortality rate to $20 \%$.The purpose of outreach/health education was SADARI this was aimed at the citizens of RT 15 Kelurahan Buluran get familiar with the hope of providing information and can be applied directly to the mothers in order to detect early cancer occurrence in order to be able to be treated as early as possible and can decrease the number of pain or death in women.Methods of implementation with discussion, faqs, provide leaflets and demonstrations as well as do SADARI engineering examination. After the execution of counseling health with mom mother on $R T 10$ and 15 have learned techniques SADARI and can practice breast self examination so that treatment can be optimal.The effort can be done one of them keep diet, eating instant foods, food ingredients that contain MSG, can also do a breast exam alone or commonly abbreviated to realize.
\end{abstract}

Keyword: early detection, technical ecstasy, breast cancer

\begin{abstract}
ABSTRAK
Kanker payudara masih menjadi masalah besar di Indonesia, karena 68,6\% wanita dengan penyakit kanker payudara berobat kedokter pada stadium lanjut local ( IIIa dan IIIb), sedangkan pada stadium dini ( I dan II) hanya 22,4\%. Tingginya angka kejadian kanker payudara ini harus menjadi perhatian bagi pemerintah dan masyarakat umumnya. Tujuan dari SADARI adalah untuk mengetahui / sebagai pendeteksi secara dini adanya kanker payudara yang dapat dilakukan pada wanita usia subur. Ternyata $75-82 \%$ keganasan payudara ditemukan pada saat pemeriksaan SADARI dan dapat menurunkan tingkat kematian sampai $20 \%$. Tujuan penyuluhan / pendidikan kesehatan SADARI ini ditujukan pada warga RT 15 Kelurahan Buluran Kenali dengan harapan dapat memberikan informasi dan dapat mengaplikasikan langsung kepada ibu-ibu agar dapat mendeteksi secara dini agar kejadian kanker dapat diobati sedini mungkin dan dapat menurunkan angka kesakitan maupun kematian pada wanita. Metode pelaksanaan dengan melakukan diskusi, tanya jawab, memberikan leaflet dan demonstrasi pemeriksaan tehnik SADARI serta melakukan pemeriksaan SADARI. Setelah pelaksanaan penyuluhan kesehatan bersama ibu ibu di RT 10 dan 15 telah mengetahui tehnik SADARI dan dapat mempraktikkan pemeriksaan payudara sendiri sehingga pengobatan dapat optimal. Upaya yang dapat dilakukan salah satunya menjaga pola makan, mengurangi makan makanan instan, bahan makanan yang mengandung MSG, juga dapat dilakukan pemeriksaan payudara sendiri atau yang biasa disingkat SADARI.
\end{abstract}

Kata Kunci: Deteksi dini, tehnik sadari, kanker payudara 


\section{PENDAHULUAN}

Kanker payudara termasuk diantara penyakit kanker yang banyak diperbincangkan karena keganasannya seringkali berakibat kematian . Kanker payudara merupakan masalah kesehatan baik dinegara berkembang ataupun negara maju. Angka penderita kanker payudara di Indonesia menurut Departemen Kesehatan sebesar 876.665 orang ( Kusminator, 2006). Rata -rata penderita kanker payudara di Indonesia adalah 26 dari 100 ribu perempuan, dan menjadikan penyakit ini berada pada urutan kedua setelah kanker mulut rahim ( kanker serviks). Kanker payudara masih menjadi masalah besar di Indonesia , karena 68,6\% wanita dengan penyakit kanker payudara berobat kedokter pada stadium lanjut local ( IIIa dan IIIb), sedangkan pada stadium dini ( I dan II) hanya 22,4\% (Azamris,2006) . Pada tahun 2008 ditemukan sebanyak 39,381 kasus baru kanker payudara dan 20,052 terjadi kematian ( Nugroho, 2012).

Data dinas kesehatan Provinsi Jambi tahun 2011 ditemukan kasus kanker payudara sebanyak 1409 kasus di seluruh rumah sakit yang berada di provinsi Jambi. Sedangkan data yang diperoleh dari RSUD Raden Mataher Jambi tahun 2014 penderita kanker payudara sebanyak 64 orang, tahun 2015 ada 65 orang dan tahun 2016 sampai bulan Maret ada sebanyak 38 orang. Terlihat jumlah penderita yang dirawat inap mengalami peningkatan dari tahun ketahun (Dinkes Prop. Jambi, 2011). Tingginya angka kejadian kanker payudara ini harus menjadi perhatian bagi pemerintah dan masyarakat umumnya. Upaya yang dapat dilakukan salah satunya menjaga pola makan, mengurangi makan makanan instan, bahan makanan yang mengandung MSG, juga dapat dilakukan pemeriksaan pemeriksaan payudara sendiri atau yang biasa disingkat SADARI (Ba'diah, 2013)

Pemeriksaan payudara sendiri (SADARI) dapat dilakukan untuk menurunkan angka mortalitas kanker payudara . Tujuan dari SADARI adalah untuk mengetahui / pendeteksi secara dini adanya kanker payudara yang dapat dilakukan pada wanita usia subur. Ternyata $75-82 \%$ keganasan payudara ditemukan pada saat pemeriksaan SADARI dan dapat menurunkan tingkat kematian sampai $20 \%$. Sebelum kanker bermetastasis, penemuan kanker payudara sedini mungkin yang didiagnosis dan diobati secara benar akan menambah umur harapan hidup penderita kanker pada stadium I sebesar 70-80\%, stadium II $43 \%$, stadium III kurang dari $11,2 \%$ dan stadium IV 0\% (Soetjipto,2001)

Walaupun ada peningkatan kewaspadaan terhadap kanker payudara, hanya sebagian kecil saja yang melakukan SADARI secara teratur. Pemeriksaan payudara sendiri (SADARI) ini sebaiknya dilakukan setiap bulan yaitu pada hari ke 510 setelah menstruasi bagi wanita berumur 20 tahun keatas. Factor-faktor yang mempengaruhi seseorang melakukan pemeriksaan SADARI antara lain pengetahuan, pendidikan, persepsi, keyakinan dan kebudayaan.

Wanita yang ingin melakukan SADARI menemukan benjolan oleh diri sendiri menyebabkan kecemasan berlebihan, sehingga mereka memilih untuk tidak SADARI, masih rendahnya kewaspadaan wanita terhadap kanker dan sedikitnya akses informasi yang didapat ( Desanti,2010).

Salah satu upaya untuk meningkatkan pengetahuan tentang SADARI salah satunya dapat melalui pendidikan kesehatan, baik berupa peyuluhan, penyebaran leafleat / brosur, sarana internet, TV dan banyak lagi sehingga akan terwujud prilaku masyarakat yang kondusif 
untuk kesehatannya. Survey awal yang didapat dari ibu-ibu lingkungan RT 15 Kelurahan Buluran Kenali didapatkan hasil rata-rata ibu -ibu belum tahu tujuan, manfaat dan cara pemeriksaan payudara sendiri. Mereka juga beranggapan tanpa pemeriksaanpun tetap baik-baik saja. Namun ibu-ibu juga mengatakan takut kalau sampai terkena kanker payudara sehingga mereka meminta sendiri untuk diadakannya penyuluhan ataupun demonstrasi tehnik SADARI.

Adapun permasalahan mitra dikarenakan kurangnya pengetahuan dan pemahaman ibu ibu di RT 10 dan 15 Kelurahan Buluran Kenali tentang pemeriksaan payudara sendiri (SADARI).

\section{TARGET DAN LUARAN}

\section{TARGET SEBELUM SESUDAH}

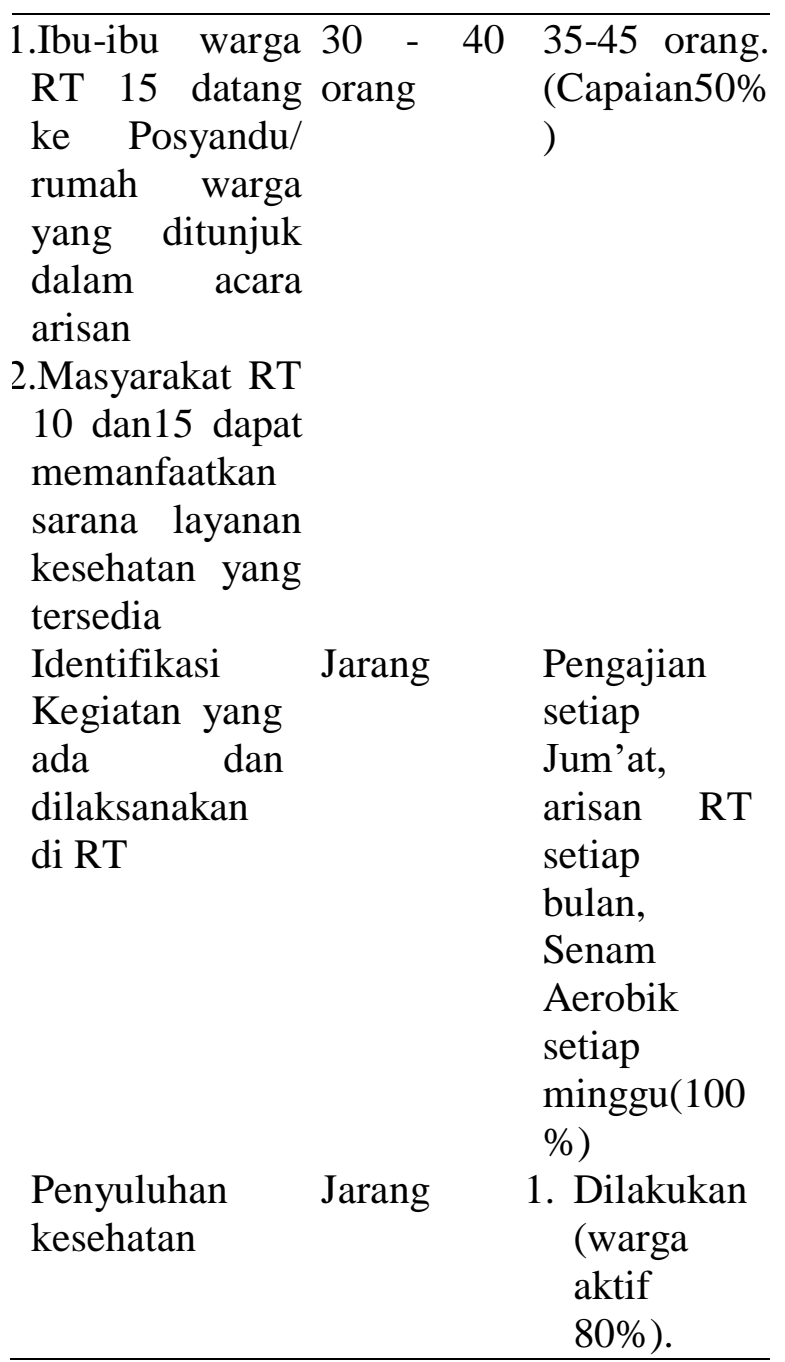

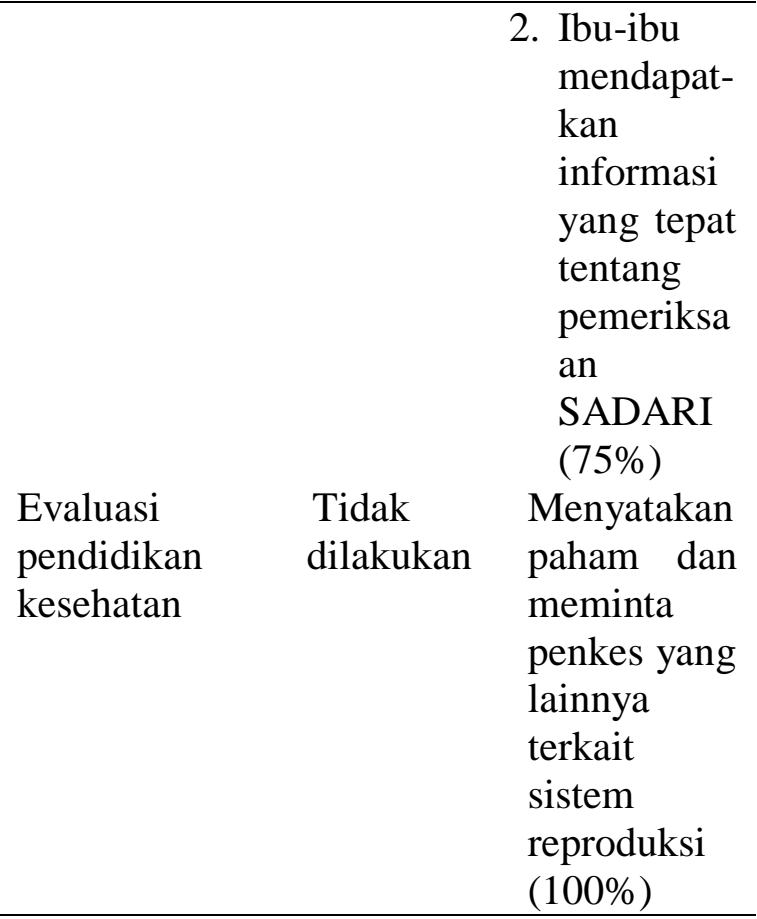

\section{METODE PELAKSANAAN}

Solusi yang dirancang dalam kegiatan pengabdian masyarakat ini sesuai dengan tahapan sebagai berikut:

1. Temu ketua RT dan kader,dengan melakukan identifikasi kegiatan dan penjadwalan kegiatan. Metode yang digunakan dengan cara Diskusi di rumah pak RT 15

2. Perumusan Solusi, dengan melakukan identifikasi masalah kanker payudara dan tehnik SADARI, menyusun strategi pelaksanaan dan pmbuatan leaflet. Metode yang digunakan dengan melakukan diskusi dan tanya jawab di rumah pak RT 15 dan juga ke rumah warga.

3. Pemberian informasi / penyuluhan kesehatan dengan materi Pemeriksaan SADARI, melalui ceramah, diskusi dan tanya jawab, pemberian leaflet serta demonstrasi tehnik sadari yang dilakukan di rumah warga pada saat arisan RT.

4. Evaluasi dan monitoring dengan melakukan pembinaan dan pengawasan dengan cara melakukan redemonstrasi 
pemeriksaan sadari yang dilakukan di salah satu rumah warga.

\section{HASIL DAN PEMBAHASAN}

Kegiatan pengabdian masyarakat ini dilaksanakan di bulan April 2017 bertujuan memberikan wawasan dan pengetahuan pada ibu-ibu pasangan usia subur di wilayah RT 10 dan 15 Kelurahan Buluran Kenali Telanaipura Jambi. Kegiatan ini terlaksana dengan catatan hasil identifikasi masih banyak ibu ibu yang belum paham atau belum pernah melakukan pemeriksaan sadari, namun setelah diberikan pendidikan kesehatan ibu ibu tersebut mulai paham dan ikut bersama sama mendemonstrasikan pemeriksaan sadari, dengan harapan dapat mempraktikkan nanti di rumahnya sehingga dapat menolong dirinya sendiri dan keluarganya agar terhindar dari kanker payudara.

Gambar 1. Pelaksanaan Penyuluhan

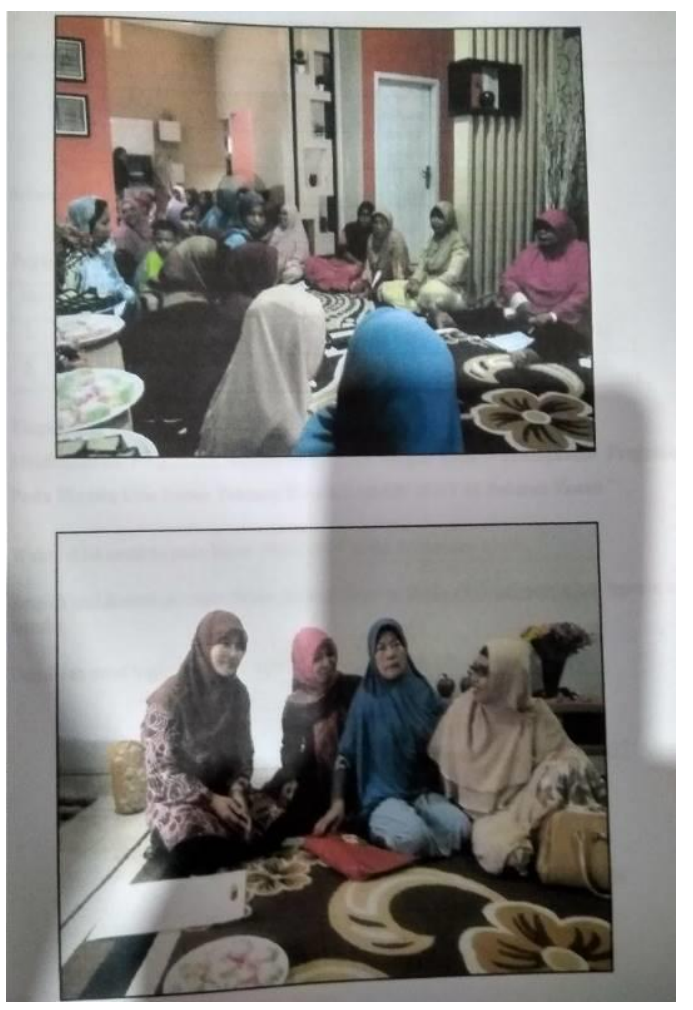

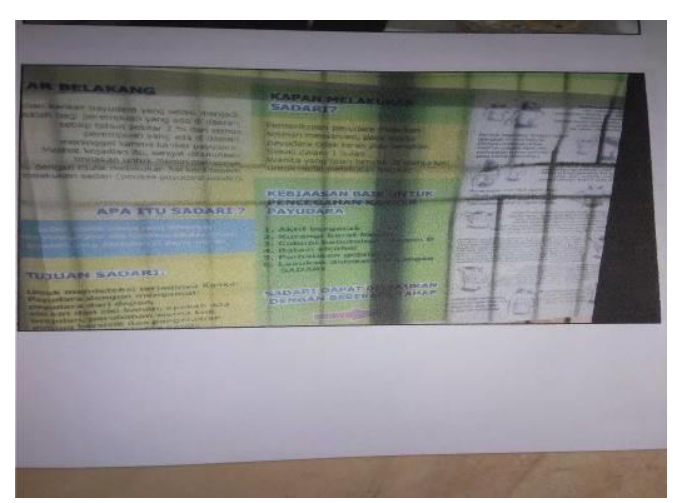

\section{KESIMPULAN DAN SARAN}

\section{Kesimpulan}

Dengan adanya pengabdian masyarakat di RT.15 khususnya ibu ibu yang berada di RT 15 termotivasi dan menggerakkan warga di wilayah RT.15 ikut serta kegiatan penyuluhan kesehatan khususnya tentang Tehnik pemeriksaan SADARI dan aktif dalam kegiatan lainnya.

Hasil pengabdian masyarakat ini adalah para kader dan ibu-ibu usia subur memahami dan mengerti tentang tehnik SADARI.

\section{Saran}

1. Bagi Puskesmas Simpang IV Sipin Jambi

Agar dapat lebih mengoptimalkan lagi peran puskesmas dalam memberikan pendidikan kesehatan khususnya tentang Tehnik SADARI sehingga program yang ada dapat terlaksana dan masyarakat paham dan ikut serta dalam program pemerintah

2. Bagi Insitusi STIKBA Jambi

Sebagai bahan bacaan dan kajian bagi ilmu kesehatan serta memotivasi bagi dosen agar dapat menjalankan perannya dalam tri darma perguruan tinggi dan pengabdian masyarakat dan memotivasi mahasiswa ikut terlibat dalam pengabdian tersebut. 


\section{UCAPAN TERIMAKASIH}

Termakasih kepada Sekolah Tinggi Ilmu Kesehatan Baiturrahim dan bapak ketua RT 15 yang telah memberikan dana dan memfasilitasi kegiatan pengabdian kepda masyarakat ini.

\section{DAFTAR PUSTAKA}

Azamris. 2006. Analisis Faktor Risiko Pada Pasien Kanker Payudara di RS M. Djamil Padang.Cermin Dunia Kedokteran.

Ba'diah, dkk.2013. Konsep SADARI. Nuha Medika. Yogyakarta

Depkes, RI. 2013.Angka Kejadian Kanker Payudara di Indonesia. http://www.depkes.go.id/index.php?v $\underline{w}=2 \& i d=2233.2013 . J a k a r t a$

Dinkes Provinsi Jambi. 2011. Data Penderita Kanker Payudara di Provinsi Jambi.

Kusminarto. 2006. Deteksi Sangat Dini Kanker Payudara, Jawaban untuk Menghindar.Departemen Kesehatan. 2006. [internet]. Available from: <http://www.litbang.depkes.go.id/ aktual /kliping/payudara190906.htm> Diakses pada 16 September 2006.

Nugroho.2011. Masalah Kesehatan Reproduksi Wanita. Nuha Medika. Yogyakarta

Rasjidi, Imam \& Hartanto, Andre, 2009. Kanker Payudara,ed. Deteksi Dini dan Pencegahan Kanker Pada Wanita. Sagung Seto,jurnal Online. Diakses tanggal 2 Mei 2016

Soetjipto, 2001. Deteksi Dini dan Pengobatan Kanker Payudara. Makalah disampaikan dalam ceramah sehari di RS Kanker Dharmais, Jakarta, 6 Maret 2001.2001. 